\title{
Experimental Study on the Breaking Ability of the Cutting Angle of Conical Picks
}

\author{
K. X. Kang ${ }^{1,2, *}, B . H e^{1,2}$, and S. J. Wang ${ }^{1}$ \\ ${ }^{1}$ Jiangsu Xugong Construction Machinery Research Institute Co., Ltd, Xuzhou 221004, China \\ ${ }^{2}$ Sate Key Laboratory of Intelligent Manufacturing of Advanced Construction Machinery, Xuzhou 221004, China
}

\begin{abstract}
This Effects of cutting angle of conical picks affecting on rock breaking capacity was researched to calculate the low construction efficiency of the conical picks at hard rock cutting. Firstly, according to the construction situation of the conical picks, the rotary milling test bench of rock was built. Secondly, the physical and mechanical properties of four kinds of rocks (blue sandstone, red sandstone, limestone, granite.) were measured, and the brittleness index of the four kinds of rocks was calculated. Finally, four kinds of rocks were tested at six cutting angles, respectively. The results of the experiments indicate that the radial force is the largest, the tangential fore is the second, and the lateral force is the smallest in the three-axis of the pick against the four rocks over 50MPa. With the increase of the rock compressive strength, the ratio of radial force to tangential force increases gradually. Therefore, more down-force of machine is needed to improve the impact penetration ability of the pick. Taking milling resistance and specific energy consumption as index, the cutting angle of 63 for the green sandstone and red sandstone, and the cutting angle of 58 for the limestone and granite are helpful to improve the operation efficiency of the whole machine.
\end{abstract}

\section{Introduction}

Conical picks are the main milling tools for many rotary milling engineering machinery equipment such as shearer drums, roadheader cutting head, and milling wheels of double-wheel trench cutter. The rock breaking effect directly affects the efficiency and mining cost of the main equipment. In recent years, with the expansion of the application field of the above host products, the milling objects have become more diverse and the working conditions have become worse [1]. Especially in the hard rock condition, the impact of pick is difficult to invade the rock, the abrasion speed is fast, and the construction efficiency is low. Therefore, through a large number of rock milling experiments, it is of practical significance to study the influence of cutting angle of pick on the rock breaking ability of different kinds of rock.

In order to further study the rock breaking effect of conical picks, a large number of theoretical analysis and experimental researches on rock breaking methods of picks have been carried out at home and abroad. Evans [2] first proposed and proved the tangential force prediction formula acting on the pick. Bilgin [3] established tangential and normal force prediction formulas based on full-scale linear cutting experiments. YURDAKUL M [4] studied the effects of compressive strength, flexural strength, and point load strength on the specific energy consumption of cutting based on a large number of experiments. Liu Chunsheng [5] wedged the rock at different angles of the pick, and analyzed the force state of the pick. Liu Jinxia [6] proposed a rotary pick force model of pick picks, and obtained that the cut force has a complex trigonometric function relationship with the half cone angle and the cut angle of the pick, Wang Shujing [7] used a rotating cutting test rig to obtain the cutting threeaxis force during the rock cutting process by using a combination of experimental research and simulation analysis. Tiryaki [8] studied the properties of rock texture coefficient, feldspar content, cementation coefficient, effective porosity, and pore volume to significantly affect the specific energy consumption of the cut. Wang Xiang [9] studied the effects of related angle parameters on cutting force and specific energy consumption based on straight-line cutting experiments. Wang Liping [10] established a calculation model for the peak cutting force of pick picks considering the brittleness index of coal rocks.

Unfortunately, most of the above studies only predict the milling resistance for a specific type of rock, and do not take into account the effects of the comprehensive physical index of rock physical characteristics and cutting angle on the milling resistance and the specific energy consumption of the milling. Therefore, a rotary milling test bench for picks is used to carry out rotary milling tests on 4 different rocks. The effect of the cutting angle and the cutting ratio on the specific energy consumption of the cutting is studied, and the data support is improved to guide the power matching of the whole product, thereby improving the rock breaking ability of the cutting and the working efficiency of the whole. 


\section{Rotary milling test bench}

\subsection{Test bench principle and composition.}

In the construction process of the milling wheel of doublewheel trench cutter, the pick rotates downward with the milling wheel. The milling process and milling parameters of the pick are shown in Fig. 1. The pick invades the rock with a certain cutting angle, and then rotates at a certain rotation speed. Ft, Fr and Fs are tangential force, radial force and lateral force respectively.

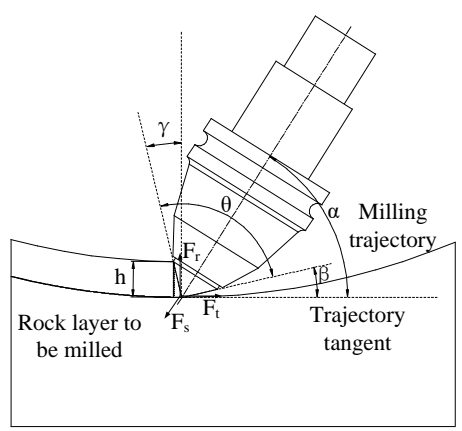

Fig. 1. Schematic diagram of cutter milling

To simulate the milling process of the pick, a rotary milling test bench is set up, as shown in Fig. 2. The rotary milling test bench includes a drive console car, a rock clamping device, and a three-axis force test system. The driving console car is the control center of the entire milling test bench, which controls the 6 translational degrees of freedom of the milling wheel and the rotary motion of the milling wheel; the rock clamping device can accommodate the largest rock sample size of $500 \mathrm{~mm} \mathrm{X}$ $1000 \mathrm{~mm}$ X $1000 \mathrm{~mm}$, and can achieve 6 Displacement adjustment with translation accuracy of $1 \mathrm{~mm}$. The threeaxis force test system is composed of three-axis force test device and sensor, multi-channel high-precision data acquisition system and computer, which can obtain tangential force, radial force and lateral force in real-time. The sampling frequency is $256 \mathrm{~Hz}$.

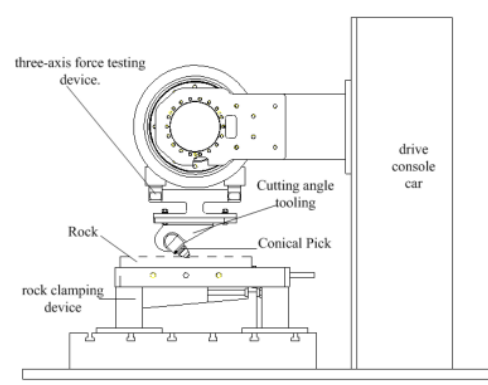

Fig. 2. Rotary milling test bench

\subsection{The three-axis force testing device.}

According to the principle of force transmission, as shown in Fig.3, the three-axis force test sensor is set between the pick and the milling wheel, and I-shaped balance beam structure is used to test the three-axis force of the pick.
Corresponding to the three-axis force direction of the pick tip, the three perpendicular directions of the balance beam are pasted with strain gauges R1-R12. Three groups of strain gauges form a full bridge measuring circuit respectively, which can convert the tangential, radial and lateral strains of the pick in the milling process into the electric energy input data collection system, and transmit them to the computer hard disk in real time for subsequent analysis and processing.

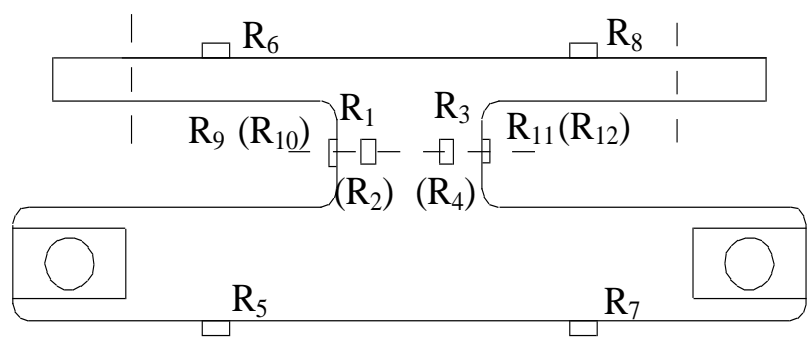

Fig. 3. The three-axis force testing device

\subsection{Pick-cutting angle tooling.}

The test pick is shown in Fig. 4. The cone angle of the alloy head is 90 , the diameter is $22 \mathrm{~mm}$, and the height is $10 \mathrm{~mm}$. As shown in Fig. 4, the pick holder with different angles is designed. The change of the cutting angle of the pick at different angles is realized by replacing the pick holder.
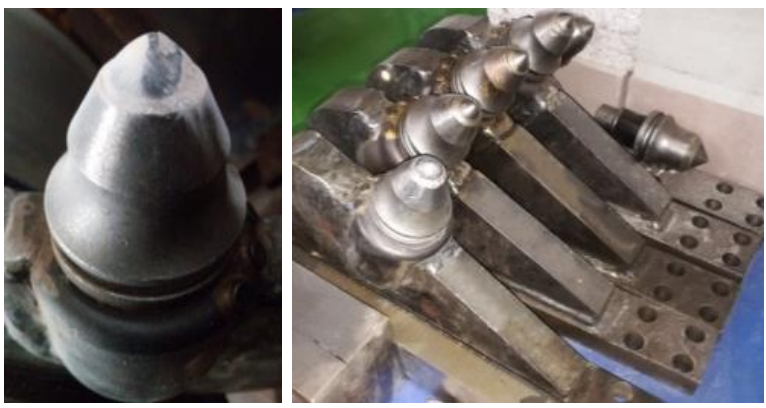

Fig. 4. The test pick and cutting angle tooling

\section{Analysis of rock physical and mechanical characteristics}

As shown in Fig. 5, the subjects of this test are natural blue sandstone, red sandstone, limestone, and granite stone, respectively cut into a cylindrical standard test piece with a diameter of $\$ 50 \mathrm{~mm}$ and a height of $100 \mathrm{~mm}$ and a Brazilian disc test piece of $25 \mathrm{~mm}$.

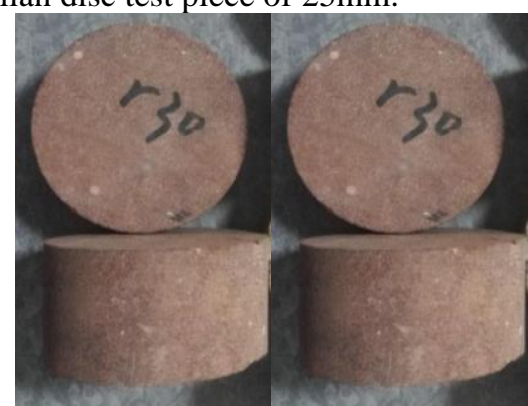


Fig. 5. Rock sample

The uniaxial compressive test, triaxial compressive test and tensile strength test were performed on MTS816 test machine (Fig. 6). Each group used 5 specimens for repeated tests. The uniaxial compressive test and triaxial compressive test load rate was $0.002 \mathrm{~mm} / \mathrm{s}$, the triaxial compression test uses 4 levels of confining pressure, which are $5 \mathrm{MPa}, 10 \mathrm{MPa}, 20 \mathrm{MPa}, 30 \mathrm{MPa}$, respectively. Under each level of confining pressure, 5 experiments are performed. The tensile strength of the rock was tested using the Brazilian disc split test method with a loading rate of $0.001 \mathrm{~mm} / \mathrm{s}$. The mechanical properties of the rock finally obtained are shown in Table 1.

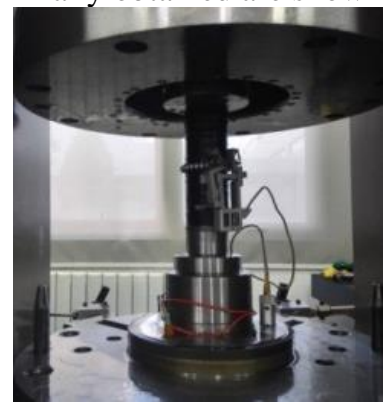

(a)

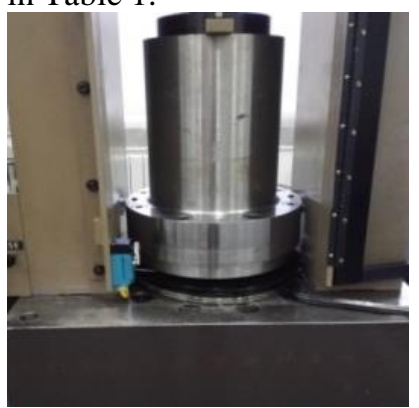

(b)

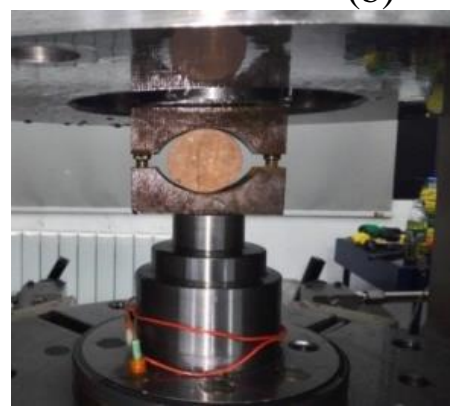

(c)

Fig. 6. Measurement of physical and mechanical parameters of rock: (a) Uniaxial compressive strength test (b) Triaxial compressive test (c) Tensile strength test

Brittleness is an important index to reflect the post peak failure of rock. When the rock reaches the peak strength, if the rock produces large plastic deformation, it will consume a large amount of elastic strain energy stored in the process of pre peak compression, so that when the rock is destroyed after the peak, the rock is destroyed stably. When the rock reaches the peak strength, it does not produce a lot of plastic deformation, and then brittle failure occurs, which will be accompanied by a large number of rapid releases of elastic properties in the process of failure. As an important basic characteristic of rock post peak failure, it is of great significance for rock breaking by construction machinery.

With the continuous development of rock mechanics, many scholars at home and abroad have done a lot of research on the evaluation of rock brittleness, and given the corresponding calculation formula of brittleness index. In this paper, the normalized indexes of peak stress and residual stress, peak strain and residual strain are considered. It can be used as a comprehensive evaluation method of rock brittleness index.

$$
\begin{gathered}
B_{I}=\frac{B_{i}-B_{\min }}{B_{\max }-B_{\min }} \\
B_{i}=B_{\text {post }}+B_{E} \\
B_{E}=\frac{\left(\sigma_{p}-\sigma_{r}\right)\left(\varepsilon_{r}-\varepsilon_{p}\right)}{\sigma_{p} \varepsilon_{p}} \\
B_{\text {post }}=\frac{\sigma_{p}-\sigma_{r}}{\varepsilon_{r}-\varepsilon_{p}}
\end{gathered}
$$

In the formula, $\sigma_{\mathrm{p}}$ and $\sigma_{\mathrm{r}}$ are peak stress and residual stress respectively, $\varepsilon_{\mathrm{p}}$ and $\varepsilon_{\mathrm{r}}$ are peak strain and residual strain respectively. Bmax and Bmin are the maximum and minimum values of the brittleness index in rock samples, $\mathrm{B}_{\mathrm{POST}}$ and $\mathrm{B}_{\mathrm{E}}$ are the post peak brittleness index and pre peak brittleness index respectively. $\mathrm{Bi}$ and $\mathrm{BI}$ are the brittleness indexes of rock samples before and after standardization respectively; the value range of $\mathrm{B}_{\mathrm{i}}$ is $0 \sim 1$, the larger the value is, the higher the brittle failure degree of rock is.

According to the uniaxial and triaxial compressive strength test results of argillaceous sandstone, red sandstone, granite, the peak stress $\sigma \mathrm{p}$, and residual stress $\sigma \mathrm{r}$, the peak strain $\varepsilon \mathrm{p}$ and the residual strain $\varepsilon \mathrm{r}$ can be obtained. The brittleness index of the rock can be calculated, as shown in Table 1.

Table 1. Physical and mechanical properties of rock

\begin{tabular}{|c|c|c|c|c|c|c|}
\hline Rock type & $\begin{array}{c}\text { Density } \\
(\mathrm{g} \cdot \mathrm{cm}-3)\end{array}$ & $\begin{array}{c}\text { Compressive } \\
\text { strength } \\
(\mathrm{MPa})\end{array}$ & $\begin{array}{c}\text { Tensile strength } \\
(\mathrm{MPa})\end{array}$ & Cohesion (MPa) & $\begin{array}{c}\text { Internal friction } \\
\text { angle }\left({ }^{\circ}\right)\end{array}$ & Brittleness index \\
\hline $\begin{array}{c}\text { Blue } \\
\text { Sandstone }\end{array}$ & 2.12 & 50.06 & 3.65 & 16.15 & 30 & 0.41 \\
\hline $\begin{array}{c}\text { Red } \\
\text { Sandstone }\end{array}$ & 2.22 & 73.93 & 4.15 & 28.3 & 32 & 0.45 \\
\hline $\begin{array}{c}\text { Limeston } \\
\text { e }\end{array}$ & 2.56 & 84.02 & 4.85 & 25.2 & 42 & 0.65 \\
\hline Granite & 2.64 & 95.07 & 5.68 & 22.49 & 47 & 0.62 \\
\hline
\end{tabular}




\section{Test method and result analysis}

\subsection{Test method.}

Set the rotation speed to $20 \mathrm{r} / \mathrm{min}$, fix 4 different rocks in the rock clamping device in turn, and install 6 sets of installation tools, such as $50^{\circ}, 53^{\circ}, 55^{\circ}, 58^{\circ}, 63^{\circ}$, and $65^{\circ}$, and adjust the cutoff. The distance between the tooth tip and the rock sample ensures that the milling thickness is $4 \mathrm{~mm}$. Each milling angle is repeated for 5 milling tests. The three-axis force data is collected in real time, and the average value is calculated. Every two tests are adjusted the lateral distance is greater than $30 \mathrm{~mm}$, which guarantees independent milling for each test.
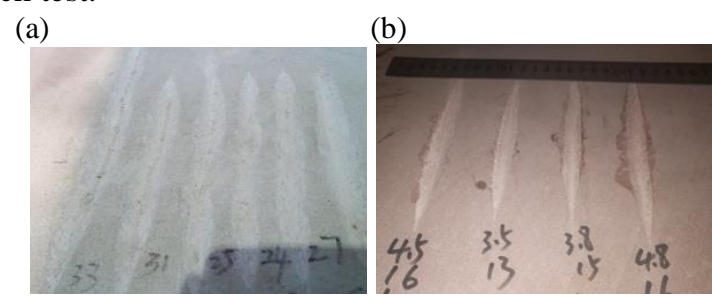

(c)
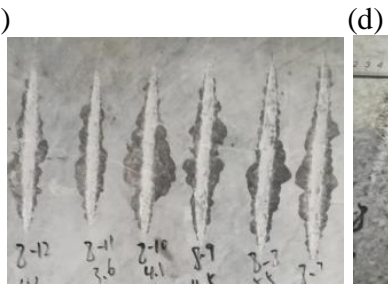

(d)

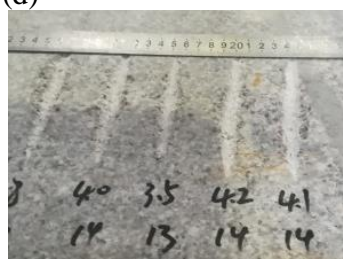

Fig. 7. Rock milling results: (a) Blue sandstone; (b) Red sandstone; (c) Limestone; (d) Granite

\subsection{Calculation of milling specific energy consumption.}

The specific energy consumption of milling refers to the energy consumed by the cutting unit to crush a unit volume, which can truly reflect the construction efficiency of the milling wheel, and is an important parameter to determine the construction efficienc

$$
\mathrm{SE}=\frac{\sum_{i=1}^{n} F_{i} L_{i}}{V}
$$

$\mathrm{F}(\mathrm{KN})$ is the tangential force during the cutting milling cycle, $\mathrm{L}(\mathrm{mm})$ is the milling length, and $\mathrm{V}(\mathrm{m} 3)$ is the volume of the rock broken during the cutting milling cycle.

The tangential force is obtained through the three-axis force test system in real-time. The corresponding rock crushing volume is scanned by a three-dimensional scanner and the rock crushing surface is then processed in reverse using Geomagic software is shown in Fig. 8.

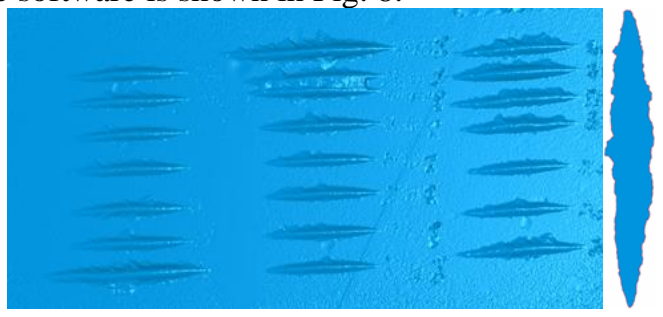

Fig. 8. Slot volume scanning and calculation

\subsection{Result analysis.}

The process of pick-milling to break the rock is mainly two processes: radial impact intrusion and tangential milling. The magnitude of the radial force of the pick can reflect the difficulty of impact penetration. The tangential force of the pick is mainly used for the work of the rotary milling process, and the lateral force is used to help generate the lateral crack. From Table 2 and Figure 7, it can be seen that for four different rocks with uniaxial compressive strength greater than $50 \mathrm{MPa}$, among the three-axis forces acting on the pick, the radial force is the largest, the tangential force is the second, and the lateral force is the smallest. With the increase of the uniaxial compressive strength of the rock, the diameter-to-cut ratio (ratio of the radial force to the tangential force) gradually increases, and at the same time is affected by the rock brittleness index. The limestone rock has the highest degree of rock collapse. The cutting ratio is slightly larger than the cutting ratio of $95 \mathrm{MPa}$ granite. Therefore, in the case of hard rock with uniaxial compressive strength greater than $50 \mathrm{MPa}$, it is necessary to increase the down-force of the whole machine and improve the power utilization rate of the whole machine.

Table 2. Experimental data

\begin{tabular}{|c|c|c|c|c|c|c|}
\hline Rock type & $\begin{array}{c}\text { Uniaxial compressive } \\
\text { strength /MPa }\end{array}$ & $\begin{array}{c}\text { Level of } \\
\text { collapse }\end{array}$ & $\begin{array}{c}\text { Radial force } \\
\text { /N }\end{array}$ & $\begin{array}{c}\text { Tangential } \\
\text { force/N }\end{array}$ & $\begin{array}{c}\text { Lateral } \\
\text { force } / \mathrm{N}\end{array}$ & $\begin{array}{c}\text { Diameter-to-cut } \\
\text { ratio }\end{array}$ \\
\hline Blue Sandstone & 50.06 & low & 2198 & 2185 & 158 & 1.00 \\
\hline Red Sandstone & 73.93 & low & 4263 & 2986 & 267 & 1.43 \\
\hline Limestone & 84.02 & high & 10555 & 3831 & 877 & 2.76 \\
\hline Granite & 95.07 & low & 15962 & 5990 & 1146 & 2.66 \\
\hline
\end{tabular}


The cutting angle of the picks determines the attitude of the picks into the rock, which is one of the key factors affecting the milling resistance. A reasonable design of the cutting angle can improve the milling efficiency and pick losses of the picks. It can be seen from Fig. 9 that with the increase of the cutting angle, the radial force, tangential force and milling specific energy consumption of the milling gradually decrease.

For blue sandstone and red sandstone, the ratios of diameter to cut are 1 and 1.43 respectively. The radial force and tangential force affect the rock breaking effect at the same time. The radial force, tangential force and milling specific energy consumption need to be considered comprehensively, and the final optimal cutting angle $63^{\circ}$ should be selected.

For limestone and granite, the cutting ratios are 2.76 and 2.66 , respectively. The radial force has a greater impact on the rock breaking effect. The radial force and the milling specific energy consumption are mainly considered. The optimal cutting angle should be $58^{\circ}$. For different compressive strength and types of rock, different cutting angles should be selected to improve work efficiency.

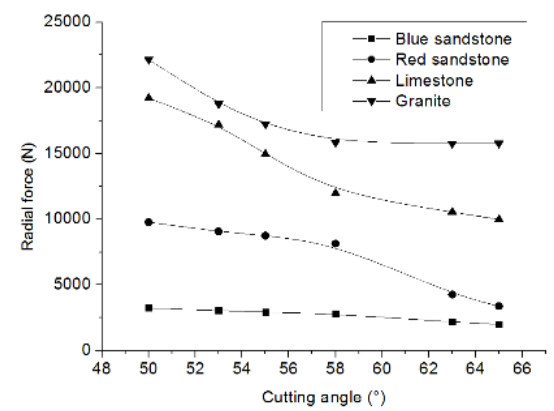

(a)

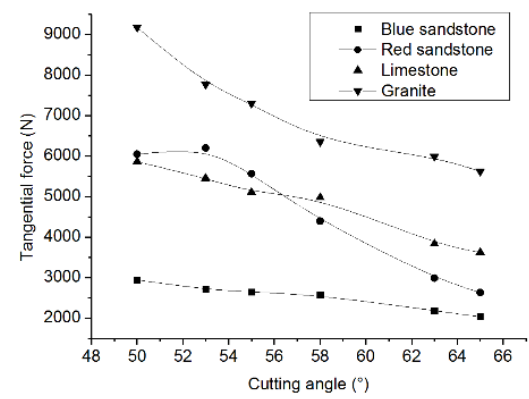

(b)

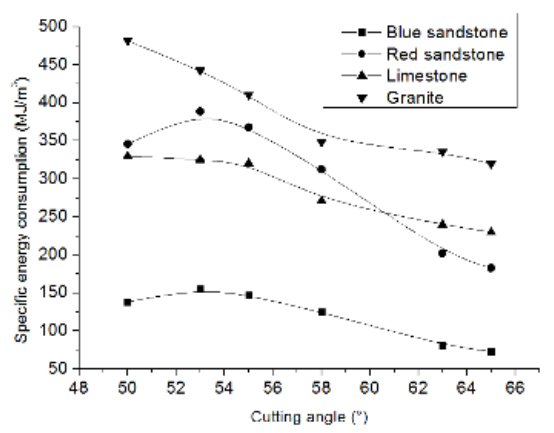

(c)

Fig.9. Relation between cutting angle and radial force (a), tangential force (b) and Specific energy consumption(c).

\section{Conclusions}

The physical and mechanical parameters of four different rocks including blue sandstone, red sandstone, limestone, and granite were tested. The normalized indexes of peak strain and residual strain were used to analyze and calculate the brittleness indexes of four kinds of rocks, and the brittleness indexes of limestone and granite. Compared with blue sandstone and red sandstone, the brittleness index is more conducive to rock collapse, and limestone has the highest collapse degree.

For four different types of rock with uniaxial compressive strength greater than $50 \mathrm{MPa}$, among the three-way forces acting on the pick, the radial force is the largest, the tangential force is the second, and the lateral force is the smallest. As the uniaxial compressive strength of the rock increases, the diameter-to-cut ratio (ratio of the radial force to the tangential force) gradually increases, and the degree of impact intrusion is more difficult. Therefore, a larger machine down-force is required to improve Tooth intrusive ability.

Through analysis and calculation of the cutting resistance of different cutting angles on the milling resistance and milling specific energy consumption of 4 kinds of rocks, the best cutting angle of blue sandstone and red sandstone should be $63^{\circ}$, and the best cutting angle of limestone and granite should be $58^{\circ}$, is conducive to improving the operating efficiency of the whole machine.

\section{References}

1. Zhang Qianqian, Han Zhennan, Zhang Mengqi, et al. Tests and simulation for wear of conical pick under impact load, J. Journal of Vibration and Shock, 2016, 35(13):58-165

2. EVANS I. A theory of the cutting force for point-attack, J. International Journal of Mining Engineering, 1984, 2(1):63-67.

3. BILGIN N, DEMIRCIN M A, COPUR H, et al. Dominant rock properties affecting the performance of conical picks and the comparison of some experimental and theoretical results, J. International Journal of Rock Mechanics and Mining Sciences, 2006, 43: 139-156.

4. YURDAKUL M, GOPALAKRISHNAN K, AKDAS N. Prediction of specific cutting energy in natural stone cutting processes using the neuro-fuzzy methodology, J. International Journal of Rock Mechanics and Mining Sciences, 2014, 67:127-135.

5. Liu Chunsheng, Song Yang. Development and simulation of cutting force model on conical pick cutting rock at different wedge angles, J.Journal of Heilongjiang Institute of Science and Technology, 2012, 22( 3) : 277 -281 .

6. Liu Jinxia, Ma Chao, Zeng Qingliang, et al. Research on cutting force of conical in cutting coal process, J. Journal of China Coal Society, 2017, 42(5):1325-1330.

7. Wang Shujing, Zong Xuemei, He Bing, et al. Test Research and Simulation of Conical Pick at Hard Rock Cutting, J. Construction Machinery and Equipment, 2019, 50(6):31-37.

8. TIRYAKI B, DIKMEN A C. Effects of rock properties on specific cutting energy in linear cutting of sandstones 
by picks, J. Rock Mechanics and Rock Engineering, 2006, 39(2):89-120.

9. Wang Xiang, Wang Qingfeng, Liang Yunpei. Effects of cutting parameters affecting on specific cutting energy of conical picks, J. Journal of China Coal Society, 2018, 43(2):563-570.
10. Wang Liping, Jiang Binsong, Zhang Yi, et al. Calculation of peak cutting force of conical picks based on Ecans' cutting model , J. Journal of China Coal Society, 2016, 41(9):2367-2372. 